\title{
Unity and Effectiveness of the Abstract Language Beginner Lecturer Research Institution (Undiksha) 2015
}

\author{
Ida Bagus Putrayasa \\ Ganesha University of Education
}

\begin{abstract}
This study examines descriptively the unity and effectiveness of sentences in the abstract faculty research institutions beginner (Undiksha) 2015.The objectives of this study to describe: (1) unity of language (sentences) on faculty research abstracts beginner Institutions (Undiksha) 2015 and (2) effectiveness languages (sentence) on faculty research abstracts beginner Institutions (Undiksha) by 2015. To achieve these objectives designed qualitative descriptive study. The data source is a faculty research abstracts beginner Institutions (Undiksha) in 2015. This study is literature. Therefore, the techniques used in collecting data is a document recording techniques. Qualitative research data were analyzed inductively. That is, the specific things that are found during the research carried out, grouped together, and made of him. In addition, the data collected is not used to prove or disprove the hypothesis made before the study began, but it is used to facilitate data description. The procedure adopted in analyzing the data is: (a)the use of the card, the card is used to record the sentences. (b) identification of errors, mistakes or inaccuracies in the use of language on faculty research abstract that appears beginners identified. (c) the classification of errors, mistakes or inaccuracies that have been identified is further classified into the realm of unity and effectiveness. (d) inference. The results show that the unity and effectiveness of faculty research abstracts sentence starters Institutions (Undiksha) 2015 was very effective. This is demonstrated by the achievement of unity of the sentence $=92.9 \%$ and the achievement of effectiveness requires $=92 \%$.
\end{abstract}

Key words:- beginner, effectiveness, lecturer, sentence, unity

\section{INTRODUCTION}

In the Law on National Education System (2003) it is mentioned that the National Education aims at educating the nation and developed a complete Indonesian man, the man who is faithful and devoted to Almighty Godand noble character, knowledge and skills, physical and spiritual health, steady and independent personality, and a sense of civic responsibility and nationality. Soedijarto (in Putrayasa, 2015) looked at national development in the field of education as making national life and improve the quality of Indonesian human in realizing advanced society, just and prosperous, and allow citizens to develop themselves, both with respect to thephysicaandspiritualaspects.Related to the nation's intellectual life, the educational resources are absolutely necessary. The support of educational resources and the implementation of education are manifested as energy, funds, infrastructure. They are provides or organizes and utilized by families, communities, learners and governments, either individually in groups. In line with this, Putrayasa (2001) and Fernandez (2002) suggested that in the implementation of teaching and education among other factors caught the teachers, students, teaching materials and teaching methods. All these factors play roles in achieving the goals of teaching and education. Therefore, the promotion of teaching and education may not be so, should consider these factors in relation to the whole. Educational resources related to facilities and infrastructures for example textbooks, journals, proceedings, and research reports. The research report (read: abstract) that is used as a source of learning, which is used in school education tracks compiled based on guidelines set by the Government. One is the use of the Indonesian language as his introduction (UUSPN, 2003).If the concept contained in the UUSPN has great meaning in the success of national development in the field of education, then of course the quality of Indonesian who carries that development must be improved so that the message can be received well by the recipient of the message (Putrayasa, 2014b). Therefore, the Indonesian language is the language of instruction in the research report, the language used should be able to help the reader to more easily understand the content 
contained therein. One way that can be done to help the reader understand the content contained in the research report (abstract) is a way to use language effectively.

So far, we do not know the effectiveness of the language (read: sentence) research reports (abstracts) lecturer beginner institutions (Undiksha) 2015 in communicating ideas or messages so that the information it up as what is meant by the researchers. Therefore, the effectiveness of language research reports (abstracts) in order to communicate ideas, concepts, or ideas need to be optimized. This is made clear by Susanto (in Putrayasa, 2015) which states that the process of change or progress in various fields takes place through communication. Related to that, the quality Indonesian research report (abstract) should be maximized, which is one way to do with improving the quality of Indonesian terms of effectiveness. Indonesian effective in the research report (abstract) is characterized among other things by the unity, effectiveness, assertiveness, and varieties (Putrayasa, 2014b). Associated with the effectiveness of the language, then that becomes the focus of study in this research is the unity and effectiveness of language (sentence) in the abstract faculty research institutions starters(Undiksha) in 2015. Unity is meant here is the idea of unity or oneness of mind expressed in a sentence. The unity could be formed if there is harmony between the subject - predicate, the predicate - object, predicate - description (Putrayasa, 2014a). In writing, it seems that long sentences do not have S and P. There is also grammatical sentences have subjects delivered by the particles. Things like this should be avoided by the users of the sentence, so that the unity of ideas that would be submitted can be captured properly by readers or listeners. Meanwhile, the intended economic frugality language or languages is an association number of words used by a wide spectrum of meanings that referenced (Putrayasa, 2014b). A sentence is said to be thrifty or economical is not because of the amount he says little, otherwise said to be frugal because of the amount he said too much. The main one is how much is appropriated word useful for readers or listeners (Chiswick and Paul, 2007). In other words, you do not use a dozen words, if the intended purpose can be achieved with a few words (Lamberton, 2002). Based on the background as described above, the core issues to be studied in this research is "How can the effectiveness of language (sentences) in a research report (abstract) lecturer beginner institutions (Undiksha) in 2015?" The major problem, it can be broken down into several subsections problem: (1) How is the unity of language (words) in the abstract faculty research institutions starters (Undiksha) 2015? (2) How frugality language (words) in the abstract faculty research institutions starters (Undiksha) 2015?

\section{RESEARCH METHODS}

The design used in this study is a qualitative research design, namely the business plan and determine all possibilities and equipment required in a qualitative research (Lincoln and Guba, 1985; Alwasilah, 2002). Data taken from the abstract studies lecturer beginner institutions (Undiksha) in 2015 from a variety of majors. Number of faculty research abstracts beginner institutions (Undiksha) 2015 that there are as many as 23 pieces. This is in accordance with the number of researchers who passed the selection for submission of proposals. Furthermore, in research reports, it is expected the novice researcher has included a research abstract. Abstracts is the source of the data in this study. The took this as abstracts the data, because both the abstract language and language research reports written by the same researchers report language can represent the same study. Due to the number of population, in this case the researcher abstract below 100, then the entire population will serve as research subjects (Krathwohl, 1998; Ary, 2005). Thus, the number of abstracts is the source of the data in this studyis23pieces.This study is literature. Therefore, the techniques used in collecting the data is the technique of recordingdocuments(Creswell,1994;Denscombe,1998).Qualitative research data were analyzed inductively (Lincoln and Guba, 1985). That is, the specific things that are found during the research carried out, grouped together, then created abstractions (Bogdan\&Biklen, 1990). In addition, the data collected is not used to prove or disprove the hypothesis made before the study began, but it is used to facilitate data description. The procedure adopted in analyzing the data were: (1)the use of the card, the card is used to record the sentences. (2) identification of errors, mistakes or inaccuracies in the use of language on faculty research abstract that appears beginners identified. (3) classification errors, mistakes or inaccuracies that have been identified is further classified into the realm of unity and effectiveness. (4) the conclusion, based on the analysis and data processing procedures as mentioned above, eventually willbe obtained a picture of the effectiveness of the use of language in the abstract faculty research institutions starters (Undiksha) 2015To determine the effectiveness of the use of language in the abstract faculty research institutions starters (Undiksha)2015usethetablebelowasaguideline. 


\section{Tabel 3.1: Criteria Level of Effectiveness Languages at Research Abstract Beginners Lecturer Institution (Undiksha) 2015}

\begin{tabular}{|c|c|}
\hline $\begin{array}{l}\text { Percentage of sentence } \\
\text { true }\end{array}$ & Predicate \\
\hline $85-100$ & Very Effektive \\
\hline $70-84$ & Effektive \\
\hline $55-69$ & Effektive Enough \\
\hline $40-54$ & Less Effective \\
\hline $0-39$ & Highly Ineffective \\
\hline
\end{tabular}

(Adapted from: Hanbook for Study of S-1 Undiksha, 2012)

\section{RESULT AND DISCUSSION}

The research data was sourced from the abstract studies lecturer beginner institutions (Undiksha) in 2015 consisting of 23 abstracts. Unity / harmony and effectiveness of sentences twenty three abstracts can be describedasfollowsAbstract number which is the source of data in this study as many as 23 pieces. Each abstract assessed the sentences in terms of the unity / harmony and effectiveness. Abstract 1 consists of six sentences, the sixth sentences and effectivein term of unity. Abstract 2 consists of six sentences: which is divided into 4 sentences arealigned, the other 2 are not aligned, as well as 4 sentences are briefand effective and 2 sentences are not effective. Abstract 3 consists of nine sentences, which is divided into 8 sentence 1 sentence aligned and not aligned, as well as 6 sentences savers and third sentences are not saving. Abstract 4 consists of eight sentences, which is divided into 7 sentence 1 sentence aligned and not aligned, as well as 8 sentences sparingly. Abstract 5 consists of 10 sentences, which consists of 10 sentences in tune, as well as 8-savers sentence and two sentences are not saving. Abstract 6 consists of six sentences, the sixth sentence in tune, as well as 5effective sentences and one sentence was not saving. Abstract 7 consists of 14 sentences, 10 sentences were divided into 4 sentences aligned and not aligned, as well as saving 13 sentences and one sentence was not saving. Abstract 8 consists of 12 sentences, which is divided into 11 sentence 1 sentence aligned and not aligned, as well as saving the twelfth sentence. Abstract 9 consists of 12 sentences, which consists of 12 sentences in tune, as well as 11-savers sentence and one sentence was not saving. Abstract $\mathbf{1 0}$ consists of nine sentences, which is divided into 9 sentences in tune as well as 9-effective sentence. Abstract $\mathbf{1 1}$ consists of 10 sentences, which consists of 10 sentences in tune, as well as brief and effective 10 sentences. Abstract 12 consists of eight sentences, which is divided into eight sentences in tune, as well as 8 sentences sparingly. Abstract 13 consists of 13 sentences, the whole sentence in tune, as well as saving 12 sentences and one sentence was not saving. Abstract 14 consists of eight sentences, which is divided into 6 sentences are aligned, and 2 sentences not aligned, as well as 6-effective sentences and two sentences are not brief and effective. Abstract 15 consists of seven sentences, the whole sentence in harmony and saving. Abstract 16 consists of seven sentences, the whole sentence in harmony and saving. Abstract 17 consists of 10 sentences, which is divided into 9 sentences are aligned, and 1 sentence not aligned, as well as 8 -savers sentence and two sentences are not saving. Abstract 18 consists of 13 sentences, the whole sentence in harmony and saving. Abstract 19 consists of 11 sentences, which is divided into 10 sentences are aligned and 1 sentence not aligned, as well as 8 sentences savers and third sentences are not saving. Abstract 20 consists of 10 sentences, which is divided into 9 sentences are aligned and 1 sentence not aligned, as well as saving the tenth sentences. Abstract 21 consists of 10 sentences, the whole sentence in harmony and saving. Abstract 22 consists of five sentences, the whole sentence in harmony and saving. Abstract $\mathbf{2 3}$ consists of 8 sentences, the whole sentence in tune, as well as 7effective sentences and one sentence was not saving. Based on the description above, it can be concluded that the language (words) in the abstract faculty research institutions starters (Undiksha) 2015 very effective views of unity / harmony sentence (92.9\%) and effectiveness of the sentence $(92 \%)$. 


\begin{abstract}
IV. DISCUSSION OF RESULTS

\section{Sentence Unity}

Unity of the sentence could be formed if there is harmony between the subject - predicate, the predicate - object, predicate - adverbial. Related to the statement, the following are presented some examples of sentences that are not relevant to the above concepts, to be taken from the data source.
\end{abstract}

Data 1: While the stock code MAYA has a beta value and lowest expected return, ie-4.79 and -37.68.

(Abs.2/K.4)

\begin{abstract}
Analysis:
Strand word on the above data do not show their unity. It is not clear which one is subject and predicate. If for example, the subject is'While the stock code MAYA', and predicate is 'have', if this can be proved by way of asking what or who in the presence of $P$ to get to know the subject, and how or why in the presence of $S$ to get to know the predicate. Obviously not, because very awkward if we're asking questions like: 'Who has?' And how or why, while the stock code MAYA?Based on the above analysis, it can be said that the strand of the word 'While the stock code MAYA', and predicate is'to have, is not effective because the sentence in terms of unity did not show any clear idea of unity. It is caused by the presence of the word while as an introduction to the subject. In addition, the strand said above data do not indicate alignment between the subject - predicate, the predicate - object, and predicate - adverbial. This is consistent with the statements made by Putrayasa (2014) that the sentence unity marked by the mandatory elements of the sentence, ie the subject and predicate. In addition, the union was supported by the alignment between the subject - predicate, the predicate - object, and predicate - adverbial. To obtain an effective sentence, in the sense of the unity of the idea is clear, it said, while in the early strand of words on the above data should be removed, so that the position of the subject becomes clear. Thus the effective sentence is 'Code MAYA stock has a beta value and lowest expected return, ie - 4.79 and -37.68 '. Another example of the unity of the sentence can be seen in the data below.
\end{abstract}

Data 2: For an equal treatment, the greater the noise, the greater the difference in power consumption savings on intelligent solar tracker. (Abs.23 / K.8).

\title{
Analysis:
}

Strand words above data do not show their unity. It is not clear which one is subject and predicate. If for example, the subject is 'For an equal treatment', and predicate is'the greater the noise, the greater the difference in power consumption savings in the solar tracker intelligent', if this can be proved by how to ask what or who in the presence of $\mathrm{P}$ to get to know the subject, and how or why before $\mathrm{S}$ to get to know the predicate. Obviously not, because very awkward if we're asking questions like: 'what or who to an equal treatment?' And how or why the greater the noise, the greater the difference in power consumption savings on intelligent solartracker?Based on the above analysis, it can be said that the strand of the words 'For an equal treatment', and predicate is 'the greater the noise, the greater the difference in power consumption savings in the solar tracker intelligent', not the sentence effective for in terms of unity did not show any clear idea of unity. In addition, the strand said above data do not indicate alignment between the subject - predicate, the predicate - object, and predicate - adverbial.

\section{Frugality Sentence}

Frugality a sentence marked the relationship number of words used by a wide spectrum of meaning applies. A sentence is said to be thrifty or economical is not because of the amount he says little, otherwise said to be frugal because of the amount he said too much. The main one is how much is appropriated word useful for the reader or listener. Related to the above statement, the following is presented strand word from the data source.

Data 3: The problem often faced by investors who invest funds in the capital market is the problem of the uncertainty direction of movement of stock prices.(Abs.2/K.1).

\section{Analysis:}

Strand word on the data above do not meet frugality. This happens because the words used in the word excessive strand. Excess words contained in the word strand is the repeating of the subject, namely the word problem. Therefore, said the problem should be eliminated once the word is that there is no repetition of the subject. This is in consistent with the theory that frugality sentence can be done by avoiding repetition of

DOI: 10.9790/0837-2203052328 $\quad$ www.iosrjournals.org $\quad 26 \mid$ Page


subjects (Putrayasa, 2014; Lamberton, 2002). In addition, the use of words in a phrase often times also showsentences are not brief and effective, as often has been said many times. So, it often means many many times. Thus the effective sentence is 'The problem often faced by investors who invest funds in the capital market is the uncertainty of the direction of the share price.'Sentences are not savingexample for repeat of the subjectcanalsobeseenonthestrandwordsbelow.

Data 4: The design of the study is a descriptive design with descriptive qualitative

Dataanalysistechniques.(Abs.3/K.3).

\section{Analysis:}

Strand word on the data above shows sentences are not brief and effectivefor a repetition of the subject, namely the use of the word draft. Said the draft should be used once only as it appears in the sentence above data. Thus theamendmensentenceis:The study design used is descriptive qualitative descriptive data analysis techniques.(Abs.3/K.3).Sentences are not savingexample for use of prepositions do not have to be seen on the strandwordsbelow.

Data 5: The purpose of this study is to assist investors in making the decision to buy or sell shares of the financial sector of the main board by using the CapitalAssetPricingModel(CAPM). (Abs.2/K.2).

\section{Analysis:}

Strand word on the data above is not efficient, because there in front of the word after word goal is not functioning in the strand of the word. Therefore, the word of just eliminate them. Word of it will work if it meets the meaning of direction or point and 'origins. In addition, the word for once the word is should be discarded as redundant. This is in accordance with the opinion of Chiswick and Paul(2007) and Lamberton(2002) which says that does not need to use a dozen words, if the intended purpose can be achieved with only a few words. Thus, the sentence amendment is' The purpose of this study is to help investors in making the decision to buy or sell shares of the financial sector of the main board by using the Capital Asset Pricing Model (CAPM). (Abs.2 / K.2).

\section{CONCLUSIONS AND SUGGESTION}

Based on data collected, described, analyzed and discussed, it can be concluded as follows. Sentences used in faculty research abstracts beginner Institutions (Undiksha) 2015 is highly effective in terms of unity or harmony sentence and effectiveness of the sentence. This is evidenced by obtaining unity or harmony sentence by $92.9 \%$ andamountedto $92 \%$ ffectivenesssentence.Achieving unity or harmony sentence amounted to $92.9 \%$ and $92 \%$ effectiveness showed that the sentences contained in the abstract research faculty beginner Institutions (Undiksha) 2015 was very effective. It needs to be maintained, if necessary, improved effectiveness in order to message, ideas, ideas presented were well received by the listener or reader. Things that need to be improved effectiveness are: (a) the alignment of the subject - predicate, the predicate - object, and predicate - adverbial, (b) avoid the use of function words as an introduction to the subject, (c) do not use the front unnecessary, (d) avoid repetition of the subject, and (e) avoid repetition of words or phrases that are not important in conveying ideas.

\section{REFERENCES}

[1] Alwasilah, C. Anyway qualitative: fundamentals of designing and conductingqualitativeresearch. Jakarta: Pustaka Jaya, 2002.

[2] Ary, D., et.al..Introduction to research in education.Yogyakarta: Student Library,2005.

[3] Bogdan, R.C. \&Biklen, S.K. Research qualitive for education. Jakarta:Inter-UniversityCenter,1990.

[4] Chriswick, B.R. \& Paul, W.M.Theeconomics of language: internationalanalyses.London:Routledge,2007.

[5] Creswell, J.W.Design reseaechqualitative and quantitativeapproaches. New Delhi: Sage Publications, 1994.

[6] Denscombe, M..Thegoodresearchguide. Philadelphia. Open UniversityPress,1998.

[7] Fernandez, L.Y..Learning Indonesian towardsan appropriateapproach to assessinglanguage and literature. Jakarta:YayasanOborIndonesia,2002.

[8] Krathwohl, D.R. Methods of educational and socialscienceresearch.Amsterdam:Longman,1998.

[9] Lamberton, D.M.The economics of language.Cheltenham,UK:E.ElgarPub,2002.

[10] Lincoln, Y.S. \&Guba, E.G..Naturalisticinquiry. NewDelhi:SagePublications, 1985. 
[11] Putrayasa,I.B..Inquiry-basedlearningIndonesian..Bandung:UPI,2001.

[12] Putrayasa, I.B. Sentence analysis (function, category, and roles). Bandung:RefikaAditama,2014a.

[13] Putrayasa, I.B.Effective sentences (diction, structure, and logic).Bandung:RefikaAditama,2014b.

[14] Putrayasa, I.B.Effectiveness of languagetextbookworklecturersUndiksha 2014. (Research Report). Singaraja:Undiksha,2015.

[15] Drafting team. Handbook studiesprogram S-1 Undiksha. Singaraja:Undiksha,2012.

[16] Law on National Education System of the Republic of Indonesia (UUSPN). Jakarta: SinarGrafika,2003. 